INTERVENTIONAL CARDIOLOGY AND SURGERY

\title{
Efficacy of drug eluting stents in patients with and without diabetes mellitus: indirect comparison of controlled trials
}

\author{
C Stettler, S Allemann, M Egger, S Windecker, B Meier, P Diem
}

See end of article for authors' affiliations

Correspondence to

Correspondence to: Department of Social and Preventive Medicine,

University of Bern,

Finkenhubelweg 11, 3012

Bern, Switzerland; egger@

ispm.unibe.ch

Accepted 17 October 2005

Published Online First

26 October 2005

\begin{abstract}
Objective: To examine whether polymer based coronary stents eluting sirolimus or paclitaxel are equally effective in patients with and without diabetes.

Methods: Systematic review and meta-analysis by indirect comparison of randomised controlled trials comparing stents eluting sirolimus or paclitaxel with conventional bare metal stents. The overall study population and patients with and without diabetes were analysed separately by using the ratio of incidence rate ratios (RIRR).

Results: The analysis was based on 10 trials (six with sirolimus, four with paclitaxel), 4513 patients (1146 patients with diabetes), 5755 years of follow up, and 2464 events. In patients without diabetes sirolimus eluting stents were superior to paclitaxel eluting stents with respect to in-stent (RIRR $0.21,95 \%$ confidence interval (CI) 0.10 to $0.48, \mathrm{p}<0.001$ ) and in-segment restenosis (RIRR $0.47,95 \% \mathrm{Cl} 0.24$ to 0.92 , $p=0.027$ ), target lesion revascularisation (RIRR $0.54,95 \% \mathrm{Cl} 0.30$ to $0.99, p=0.045$ ), and major adverse cardiac events (RIRR $0.46,95 \% \mathrm{Cl} 0.26$ to $0.83, \mathrm{p}=0.010$ ). In patients with diabetes the two drug eluting stents did not differ significantly in any of these end points. Meta-regression analysis showed a significant difference between patients with and without diabetes (tests for interaction for in-stent and insegment restenosis, $p=0.036$ and $p=0.016$ ).

Conclusion: Indirect evidence indicates that sirolimus eluting stents are superior to paclitaxel eluting stents in patients without diabetes but not in patients with diabetes.
\end{abstract}

\section{METHODS \\ Literature search and eligibility criteria}

We identified all randomised clinical trials that compared the two commercially available, polymer based drug eluting stent systems (the Cypher stent, Cordis, Miami Lakes, Florida, USA, which elutes sirolimus; and the Taxus stent, Boston Scientific, Natick, Massachusetts, USA, which elutes paclitaxel) with bare metal stents. By using Cochrane methods we searched Medline, Embase, and the Cochrane controlled trials register (from inception to April 2004) for relevant studies in any language. Electronic searches were supplemented by manual searching of reference lists, reviews, relevant book chapters, conference abstracts, and specialist journals. We also scrutinised the proceedings of the relevant FDA advisory panels.

We evaluated each trial for inclusion in the meta-analysis on the basis of five criteria: (1) study design (randomised controlled trial); (2) study population (patients with stable or unstable angina as defined elsewhere ${ }^{22} 23$ and signs of myocardial ischaemia-patients had to have a new target lesion in a native coronary artery); (3) intervention group (sirolimus or paclitaxel polymer based stent systems); (4) control group (bare metal stent); and (5) length of follow up (at least four months). Two reviewers (CS, SA) independently assessed publications for eligibility, with discrepancies being resolved in consultation with a third reviewer (PD, $\mathrm{BM})$.

\section{Data extraction and outcome measures}

Two investigators (CS and SA) independently extracted data, with disagreements resolved by a third reviewer (PD or BM). All relevant publications from a trial were considered, including, for example, early publications describing the

Abbreviations: BENESTENT II, Belgian Netherlands stent II; Cl, confidence interval; FDA, Food and Drug Administration; IRR, incidence rate ratio; $\mathrm{MACE}$, major adverse cardiac events; $\mathrm{PCl}$, percutaneous coronary intervention; RIRR, ratio of incidence rate ratios 
study design. Authors from all studies were contacted and asked to check the information extracted from published articles and, where necessary, to provide additional data. Study end points were defined as follows: (1) in-stent restenosis (stenosis of $50 \%$ or greater of the target lesion, confirmed by coronary angiography or intravascular ultrasound); (2) in-segment restenosis (stenosis of $50 \%$ or greater of the target segment, confirmed by coronary angiography or intravascular ultrasound); (3) target lesion revascularisation (coronary artery bypass grafting or repeat PCI procedure at the original lesion site, including the area inside the stent and the $5 \mathrm{~mm}$ vessel segments adjacent to it); (4) major adverse cardiac events (MACE) (Q wave and non-Q wave myocardial infarction, surgical revascularisation (coronary artery bypass graft), percutaneous revascularisation (PCI), or death).

\section{Assessment of methodological quality}

Two of us (CS and SA) independently assessed the adequacy of the concealment of allocation of patients to treatment groups and blinding of care providers and research staff ascertaining cardiovascular outcomes. Disagreements were resolved in discussion with a third reviewer (ME).

\section{Statistical analysis}

We calculated the incidence rate by dividing the number of events by the number of person years of follow up and separately analysed all patients, patients with diabetes, and patients without diabetes. For each comparison and end point the incidence rate ratio (IRR) was obtained by dividing the incidence in the drug eluting stent group by the incidence in the bare metal stent group. Studies with no outcome events in either group were excluded from the respective analysis. Comparisons with events in only one group were analysed by adding one half to all cells. We combined IRRs in fixed effects meta-analysis by using inverse variance

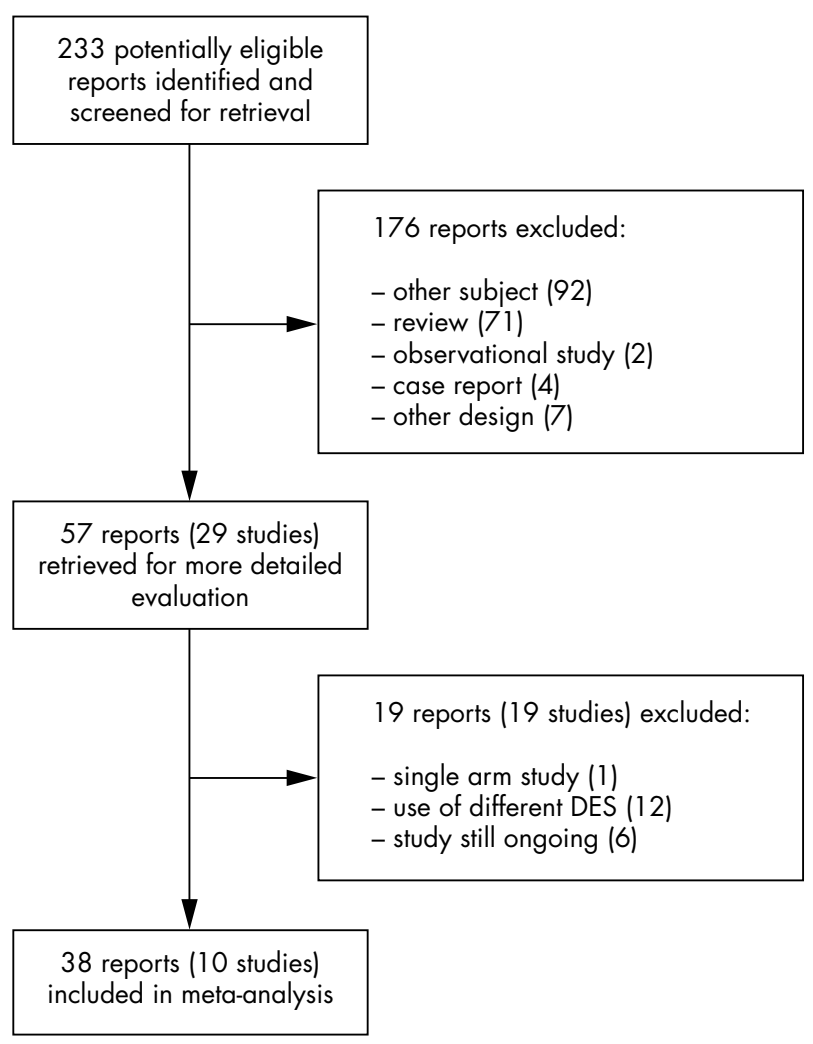

Figure 1 Identification of eligible randomised controlled trials. DES, drug eluting stents. weighting and calculated the $\mathrm{I}^{2}$ statistic, which describes the percentage of total variation across studies that is due to heterogeneity rather than chance. We also did standard tests of heterogeneity. ${ }^{24}$ The numbers of patients needed to be treated with drug eluting rather than bare metal stents to prevent one adverse event was calculated by applying the combined IRRs to the median incidence rate in the bare metal stent group of patients with or without diabetes. In sensitivity analyses we repeated calculations by using random effects models and did tests of funnel plot asymmetry. ${ }^{25}$ For comparisons between the two drug eluting stent systems we calculated the ratio of IRRs (RIRR) by using a random effects meta-regression model. ${ }^{26}$

Crude and adjusted indirect comparisons were performed by fitting random effects meta-regression models. ${ }^{26}$ Variables entered in the model were the drug (sirolimus versus paclitaxel), stent strut thickness, study characteristics (dimensions of trial quality and length of angiographic and clinical of follow up), angiographic parameters (length of target lesion, reference vessel diameter, proportion of patients with angiographic follow up, mean duration of use of clopidogrel or ticlopidine, proportion of patients receiving glycoprotein IIb/IIIa antagonists, target artery, American College of Cardiology/American Heart Association lesion classification, proportion of patients with multivessel disease, proportion of patients with stable and unstable angina, and use of direct stenting), and the characteristics of study populations at baseline (mean age, proportion of women, proportion of patients with hypertension or dyslipidaemia, and proportion of smokers). A recent analysis of data from the BENESTENT II (Belgian Netherlands stent) study showed that the inclusion of angiographic follow up increased the number of repeat revascularisations by a factor of $1.6 .^{27}$ In a sensitivity analysis we reanalysed the data with this factor to correct for angiography driven revascularisations. Results are presented as IRRs with 95\% confidence intervals (CIs) and numbers needed to treat and 95\% CIs. All analyses were performed with Stata version 8.2 (Stata Corporation, College Station, Texas, USA).

\section{RESULTS}

\section{Identification of eligible studies}

We screened the titles and abstracts of 233 potentially eligible reports, examined the full text of 57 articles reporting on 29 different studies, and identified 10 studies that met our inclusion criteria (fig 1). Additional, unpublished data were obtained for seven trials. ${ }^{1-3562930}$

\section{Characteristics of trials and patients}

Six trials $s^{1-4830}$ examined the sirolimus and four ${ }^{5-7^{31}}$ the paclitaxel eluting stent. Trials were of high methodological quality: appropriate methods of allocation concealment were described for all trials and most trials reported analyses according to the intention to treat principle. For one trial the degree of blinding of outcome assessors was unclear. ${ }^{3}$ In all trials patients with recent acute myocardial infarction or a stenosis of $50 \%$ or greater in the left main coronary artery and patients with heart failure were excluded. In all studies except one patients with diabetes constituted a subgroup of the study population. ${ }^{30}$ Stratified randomisation of patients with and without diabetes was reported in two trials. ${ }^{47}$ Five trials were performed in Europe 15830 $^{11}$ and three in North America, ${ }^{37}$ and two were multicentre trials performed in Europe and North, Central, and South America. ${ }^{26}$

The 10 trials included a total of 4513 patients, 1146 (25\%) patients with and 3367 (75\%) patients without diabetes. Table 1 shows the characteristics of the study participants. Patient characteristics were generally comparable across trials. ${ }^{1-8}{ }^{29-33}$ The mean age of patients at baseline ranged 
Table 1 Characteristics of randomised trials comparing drug eluting stents with bare metal stents

\begin{tabular}{|c|c|c|c|c|c|c|c|c|c|}
\hline \multirow[b]{2}{*}{ Study } & \multicolumn{2}{|c|}{$\begin{array}{l}\text { Diabetes } \\
\text { mellitus }\end{array}$} & \multirow{2}{*}{$\begin{array}{l}\text { Mean age at } \\
\text { baseline } \\
\text { (years) }\end{array}$} & \multirow{2}{*}{$\begin{array}{l}\text { Women } \\
(\%)\end{array}$} & \multirow{2}{*}{$\begin{array}{l}\text { Hypertension } \\
(\%)\end{array}$} & \multirow{2}{*}{$\begin{array}{l}\text { Dyslipidaemia } \\
(\%)\end{array}$} & \multirow{2}{*}{$\begin{array}{l}\text { Smoking } \\
(\%)\end{array}$} & \multicolumn{2}{|c|}{ Mean follow up (months) } \\
\hline & Yes & No & & & & & & Angiographic & Clinical \\
\hline \multicolumn{10}{|l|}{ Sirolimus eluting stents } \\
\hline SIRIUS $(2003)^{4}$ & 279 & 778 & 62.3 & 29.0 & 68.0 & 74.0 & 20.0 & 8 & 9 \\
\hline E-SIRIUS $(2003)^{1}$ & 81 & 271 & 62.3 & 29.3 & 64.0 & 74.0 & 33.0 & 8 & 9 \\
\hline C-SIRIUS $(2004)^{3}$ & 24 & 76 & 60.5 & 31.0 & 52.0 & 85.0 & 37.0 & 8 & 9 \\
\hline DIABETES $(2005)^{30}$ & 160 & & 66.6 & 37.5 & 66.3 & 61.3 & 47.5 & 9 & 9 \\
\hline RAVEL $(2002)^{2}$ & 44 & 194 & 60.7 & 24.0 & 61.0 & 40.0 & 30.0 & 6 & 12 \\
\hline SES-SMART $(2004)^{8}$ & 64 & 193 & 63.6 & 28.4 & 64.7 & 63.0 & 16.3 & 8 & 8 \\
\hline \multicolumn{10}{|l|}{ Paclitaxel eluting stents } \\
\hline TAXUS I $(2003)^{5}$ & 11 & 49 & 64.9 & 11.4 & 63.9 & 80.3 & 50.8 & 6 & 12 \\
\hline TAXUS II $(2003)^{6,32,33}$ & 76 & 453 & 60.1 & 24.4 & 61.5 & 76.6 & 24.8 & 6 & 24 \\
\hline TAXUS IV $(2004)^{7,29}$ & 318 & 996 & 62.5 & 27.9 & 69.8 & 65.3 & 21.8 & 9 & 24 \\
\hline TAXUS VI $(2005)^{31}$ & 89 & 357 & 62.6 & 23.7 & 57.8 & 71.9 & NA & 9 & 12 \\
\hline
\end{tabular}

C-SIRIUS, Canadian sirolimus coated balloon expandable stent in the treatment of patients with de novo coronary artery lesions; DIABETES, diabetes and sirolimus eluting stent trial; E-SIRIUS, European sirolimus coated balloon expandable stent in the treatment of patients with de novo coronary artery lesions; NA, not available; RAVEL, randomised study with the sirolimus eluting velocity balloon expandable stent; SES-SMART, randomised comparison of a sirolimus eluting stent and a standard stent in the prevention of restenosis in small coronary arteries; SIRIUS, sirolimus coated balloon expandable stent in the treatment of patients with de novo coronary artery lesions.

from 60-67 years. The proportions of women, smokers, and patients with hypertension or dyslipidaemia varied somewhat. Indications for PCI were similar across trials (table 2). There was a tendency towards a smaller mean reference vessel diameter in trials with sirolimus. Mean angiographic follow up and clinical follow up ranged from six to nine months and eight to 24 months, respectively.

\section{Outcomes}

Table 3 shows IRRs from individual trials for the four outcomes analysed and combined rate ratios from metaanalyses. Table 4 and table 5 show the same data for patients with and without diabetes. Figure 2 presents combined results from meta-analyses for all patients, and fig 3 shows these results separately for patients with and without diabetes. For some trials and outcomes separate data on patients with and without diabetes were not available, which meant that the number of trials that contributed to a given analysis varied. Crude and adjusted RIRR comparing sirolimus versus paclitaxel eluting stents were closely similar, and crude results are therefore presented throughout.

\section{Restenosis}

Overall, analyses were based on 604 episodes of in-stent restenosis and 657 episodes of in-segment restenosis. Compared with bare metal stents, drug eluting stents were associated with substantial reductions in the risk of restenosis in all trials reporting this outcome, but reductions were more pronounced with sirolimus than with paclitaxel eluting stents. The combined IRRs for in-stent and insegment restenosis were 0.10 (95\% CI 0.07 to 0.14 ) and 0.20 (95\% CI 0.15 to 0.26 ), respectively, with sirolimus eluting stents, and 0.27 (95\% CI 0.20 to 0.37 ) and 0.29 (95\% CI 0.22 to 0.39 ) with paclitaxel eluting stents. Of note, heterogeneity between study results in these two meta-analyses was entirely attributable to random variation $\left(\mathrm{I}^{2}=0 \%\right)$. These results translated into an RIRR of 0.35 (95\% CI 0.21 to 0.57 ) for in-stent restenosis indicating that, compared with paclitaxel, sirolimus eluting stents led to a reduction in incidence by $65 \%$. The corresponding RIRR for in-segment restenosis was 0.68 (95\% CI 0.45 to 1.01). These differences in the efficacy of preventing restenosis between the two stent systems were attributable to lower rates of restenosis with sirolimus compared with paclitaxel eluting stents in patients without diabetes, whereas results were comparable in patients with diabetes (tables 4 and 5, fig 3). Meta-regression analysis showed a significant difference between patients with and without diabetes (tests for interaction for in-stent and in-segment restenosis, $\mathrm{p}=0.036$ and $\mathrm{p}=0.016$ ).

\section{Revascularisation}

Overall, analyses were based on 522 target lesion revascularisations. Compared with bare metal stents, drug eluting stents were associated with a substantial reduction in the risk of revascularisation, but reductions were more pronounced with sirolimus than with paclitaxel eluting stents (RIRR 0.71, 95\% CI 0.46 to 1.09). This difference was also more pronounced in patients without diabetes (RIRR 0.54, 95\% CI 0.30 to 0.99 ) than in patients with diabetes (RIRR 0.86, 95\% CI 0.40 to 1.86 ), although the formal test for interaction did not reach conventional levels of significance $(p=0.36)$. Results were closely similar when correcting for angiography driven revascularisations.

\section{Major adverse cardiac events}

Analyses were based on 681 MACE, including 148 myocardial infarctions, and 41 deaths. The TAXUS trialists included stent thrombosis in their definition of MACE (17 events). Reductions were also more pronounced with sirolimus eluting stents than with paclitaxel stents (RIRR 0.54, 95\% CI 0.39 to 0.76 ), and the difference between the two types of drug eluting stents was more pronounced in patients without diabetes (RIRR $0.46,95 \%$ CI 0.26 to 0.83 ) than in patients with diabetes (RIRR $0.60,95 \%$ CI 0.21 to 1.71 , test for interaction $\mathrm{p}=0.68$ ).

\section{Numbers needed to treat to prevent one event}

Table 6 shows the estimated numbers of patients needed to treat with drug eluting rather than bare metal stents to prevent one outcome event. Numbers needed to treat were lowest for sirolimus eluting stents in patients with diabetes, followed by paclitaxel eluting stents in patients with diabetes, sirolimus eluting stents in patients without diabetes, and paclitaxel eluting stents in patients without diabetes. For one end point (MACE) the CI for the IRR of paclitaxel eluting stents was compatible with benefit and harm. We accounted for this by calculating numbers needed to benefit (corresponding to the lower limit of the CI) and numbers needed to harm (corresponding to the upper limit of the CI). ${ }^{34}$

\section{DISCUSSION}

The indirect comparisons presented here indicate that sirolimus eluting stents are superior to paclitaxel eluting 


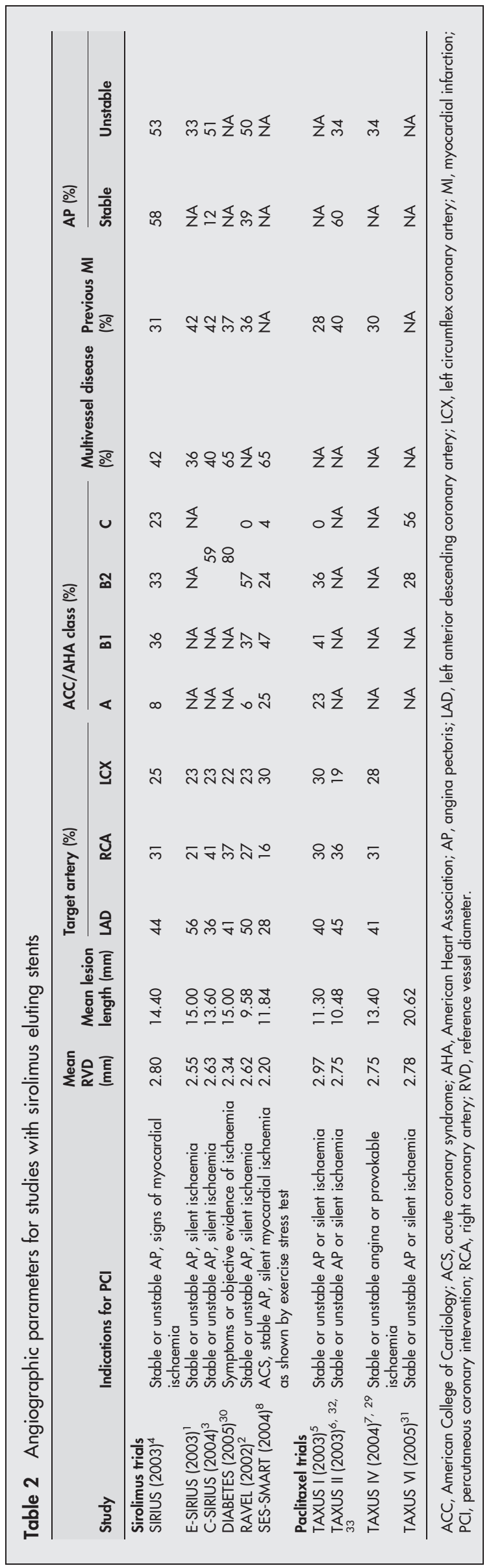

stents, and that the difference in the effectiveness between the two drug eluting stent systems is clearly evident in patients without diabetes but less certain in patients with diabetes. Calculations of numbers needed to treat show that, compared with sirolimus eluting stents, about 10 additional patients without diabetes have to be treated with paclitaxel eluting stents to prevent one MACE.

\section{Strengths and limitations}

Our review was based on a comprehensive literature search and included assessments of trial quality and a substantial amount of additional information supplied by the original investigators. Although most trials included in this analysis were not designed to examine the effectiveness of drug eluting stents in patients with and without diabetes, randomisation was stratified according to the presence or absence of diabetes in some studies, ${ }^{41}$ and all studies prospectively recorded outcomes according to standardised definitions. Indirect comparisons between sirolimus and paclitaxel eluting stents were appropriate because trials were of high methodological quality and had enrolled similar patient populations. Indeed, results were robust when adjusted for study characteristics and patient characteristics at baseline. We acknowledge that such comparisons are observational in nature and therefore have to be interpreted with caution. Only 10 trials were identified and average follow up was relatively short, which means that there was limited power to detect or exclude differences in effectiveness for rarer but clinically relevant end points, including myocardial infarction, stent thrombosis, and death.

The effect of drug eluting stents on MACE was mainly due to a reduction of revascularisation procedures. As Babapulle et $a l^{9}$ pointed out, the clinical significance of these additional revascularisation procedures is unclear because angiography was done routinely in these trials, at least in a proportion of the study population. Angiographic follow up may influence the rate of revascularisation, especially in patients with diabetes and autonomic neuropathy. ${ }^{35}$ The impact of angiography on revascularisation rates has recently been quantified. ${ }^{28}$ When we used these estimates to correct incidences for angiography driven revascularisation, results were not materially altered. We could not examine the influence of glycaemic control on the rate of restenosis and revascularisation; although a protective effect of optimised glycaemic control in patients with diabetes has been shown, no detailed information on glycaemic control was available for the trials we analysed. ${ }^{36}$

\section{Results in context with other studies}

Two meta-analyses have shown that the presence of diabetes is a risk factor for restenosis, both with drug eluting and bare metal stents. ${ }^{21}{ }^{37}$ Our findings confirm these results: diabetes clearly remains a risk factor for restenosis in the drug eluting stent era. Methodological research has shown that indirect comparisons adjusted at the aggregate level usually agree with the results of head to head randomised trials. ${ }^{38}$ In this study overall results were indeed closely similar to those reported in a recent meta-analysis of six head to head trials. ${ }^{14}$ Data from head to head comparisons in patients with diabetes are, however, more limited, and results are more heterogeneous. The large REALITY trial showed no overall difference in restenosis rates between the two stent systems, although sirolimus eluting stents appeared to be superior in patients without diabetes. ${ }^{39}$ The SIRTAX trial, in contrast, found the sirolimus eluting stent to be superior overall, with a more pronounced reduction of the rate of restenosis and revascularisation in patients with diabetes than in patients without diabetes. ${ }^{12}$ In both trials the number of patients with diabetes was relatively small, and formal tests of interaction 
Table 3 Incidence rate ratios (IRRs) from trials of sirolimus and paclitaxel eluting stents and ratio of incidence rate ratios (RIRR) comparing sirolimus with paclitaxel in all patients

\begin{tabular}{|c|c|c|c|c|}
\hline \multirow[b]{2}{*}{ Study } & \multicolumn{4}{|c|}{ IRR ( $95 \%$ confidence interval) } \\
\hline & In-stent restenosis & In-segment restenosis & TLR & MACE \\
\hline \multicolumn{5}{|l|}{ Sirolimus trials } \\
\hline SIRIUS $(2003)^{4}$ & $0.09(0.05$ to 0.16$)$ & $0.24(0.16$ to 0.36$)$ & $0.24(0.15$ to 0.39$)$ & $0.38(0.26$ to 0.55$)$ \\
\hline E-SIRIUS $(2003)^{1}$ & 0.09 (0.04 to 0.22$)$ & 0.14 (0.07 to 0.28$)$ & 0.19 (0.09 to 0.43$)$ & $0.35(0.19$ to 0.65$)$ \\
\hline C-SIRIUS $(2004)^{3}$ & $0.02(0.001$ to 0.40$)$ & $0.04(0.01$ to 0.32$)$ & $0.22(0.05$ to 1.03$)$ & 0.22 (0.05 to 1.03$)$ \\
\hline DIABETES $(2005)^{30}$ & 0.15 (0.06 to 0.39$)$ & $0.22(0.10$ to 0.47$)$ & $0.24(0.10$ to 0.59$)$ & 0.31 (0.15 to 0.66$)$ \\
\hline RAVEL $(2002)^{2}$ & $0.02(0.001$ to 0.26$)$ & $0.02(0.001$ to 0.26$)$ & $0.02(0.001$ to 0.29$)$ & 0.20 (0.09 to 0.44$)$ \\
\hline SES-SMART $(2004)^{8}$ & $0.10(0.04$ to 0.23$)$ & $0.18(0.10$ to 0.34$)$ & $0.33(0.16$ to 0.70$)$ & $0.30(0.16$ to 0.57$)$ \\
\hline Combined IRR & $0.10(0.07$ to 0.14$)$ & $0.20(0.15$ to 0.26$)$ & 0.24 (0.17 to 0.33$)$ & 0.33 (0.25 to 0.42$)$ \\
\hline Heterogeneity* & $0.0 \%, p=0.63$ & $33.6 \%, p=0.18$ & $0.0 \%, p=0.51$ & $0.0 \%, p=0.78$ \\
\hline \multicolumn{5}{|l|}{ Paclitaxel trials } \\
\hline TAXUS I $(2003)^{5}$ & $0.14(0.01$ to 2.67$)$ & NA & $0.14(0.01$ to 2.77$)$ & $0.25(0.03$ to 2.24$)$ \\
\hline TAXUS II $(2003)^{6,32,33}$ & $0.33(0.19$ to 0.55$)$ & $0.18(0.09$ to 0.36$)$ & $0.27(0.13$ to 0.53$)$ & $0.58(0.38$ to 0.86$)$ \\
\hline TAXUS IV $(2004)^{7}, 29$ & $0.23(0.13$ to 0.39$)$ & $0.30(0.19$ to 0.47$)$ & $0.32(0.22$ to 0.46$)$ & $0.56(0.41$ to 0.78$)$ \\
\hline TAXUS VI $(2005)^{31}$ & $0.28(0.17$ to 0.46$)$ & 0.35 (0.22 to 0.54$)$ & $0.42(0.25$ to 0.72$)$ & $0.73(0.48$ to 1.12$)$ \\
\hline Combined IRR & $0.27(0.20$ to 0.37$)$ & $0.29(0.22$ to 0.39$)$ & $0.33(0.25$ to 0.44$)$ & $0.60(0.48$ to 0.75$)$ \\
\hline Heterogeneity* & $0.0 \%, p=0.77$ & $16.3 \%, p=0.30$ & $0.0 \%, p=0.67$ & $0.0 \%, p=0.65$ \\
\hline RIRR (sirolimus $v$ paclitaxel) & $\begin{array}{l}0.35(0.21 \text { to } 0.57) \\
p<0.001\end{array}$ & $\begin{array}{l}0.68(0.45 \text { to } 1.01) \\
p=0.057\end{array}$ & $0.71(0.46$ to 1.09$)$ & $0.54(0.39$ to 0.76$)$ \\
\hline
\end{tabular}

were non-significant. Lastly, the ISAR-DIABETES trial in 250 patients with diabetes showed larger reductions in angiographic restenosis $(p=0.03)$ and target lesion revascularisation $(\mathrm{p}=0.13)$ with sirolimus than with paclitaxel. ${ }^{13}$

\section{Possible mechanisms}

In-stent restenosis results from neointimal hyperplasia, and the pharmacological inhibition of vascular smooth muscle proliferation by local drug delivery has proved effective in reducing restenosis and thus repeat revascularisation procedures. ${ }^{40} 41$ The biological mechanisms of action differ between paclitaxel and sirolimus: paclitaxel treated cells form abnormally stable and non-functional microtubules, which inhibit cellular replication and proliferation..$^{42}$ In contrast, sirolimus is a macrocyclic lactone that inhibits cytokine mediated and growth factor induced proliferation of smooth muscle cells and has immunoregulatory and anti-inflammatory properties..$^{43-45}$ One would expect these properties to be particularly beneficial in diabetic atherosclerosis, which is characterised by increased inflammatory markers. ${ }^{46}$ On the other hand, treatment of human platelets with sirolimus has been shown to result in enhanced agonist induced platelet aggregation and secretion. ${ }^{47}$ The more complex and advanced nature of lesions in patients with diabetes may interact with the biological mechanisms of action of both drugs but hamper effects of sirolimus more than effects of paclitaxel. Differences in local drug concentrations may also have a role: both drugs are highly lipophilic but different protein binding characteristics mean that sirolimus is distributed evenly through the vessel wall, whereas paclitaxel remains primarily subintimal. ${ }^{48}$ These distribution patterns and tissue residence time may be modified in atherosclerotic lesions of patients with diabetes. It is also possible that differences in the doses of the two drugs or differences in concomitant medications have a role.

Stents with thinner struts elicit less angiographic and clinical restenosis than stents with thicker struts. ${ }^{49} 50$ Differences in strut thickness can therefore have affected indirect comparisons. This is, however, unlikely because differences were small ( 140 and $130 \mu \mathrm{m}$ for the sirolimus and the paclitaxel eluting stent, respectively). Event rates tended to be somewhat higher in the bare metal stent groups of the

Table 4 IRRs from trials of sirolimus and paclitaxel eluting stents and RIRR comparing sirolimus with paclitaxel in patients without diabetes

\begin{tabular}{|c|c|c|c|c|}
\hline \multirow[b]{2}{*}{ Study } & \multicolumn{4}{|c|}{ IRR ( $95 \%$ confidence interval) } \\
\hline & In-stent restenosis & In-segment restenosis & TLR & MACE \\
\hline $\begin{array}{l}\text { Sirolimus trials } \\
\text { SIRIUS }(2003)^{4} \\
\text { E-SIRIUS (2003) } \\
\text { C-SIRIUS }(2004)^{3} \\
\text { RAVEL }(2004)^{2} \\
\text { SES-SMART (2002) } \\
\text { Combined IRR } \\
\text { Heterogeneity } \\
\text { Paclitaxel trials } \\
\text { TAXUS I (2003) } \\
\text { TAXUS II }(2003)^{6,32,33} \\
\text { TAXUS IV }(2004)^{7,}, 29 \\
\text { TAXUS VI }(2004)^{31} \\
\text { Combined IRR } \\
\text { Heterogeneity } \\
\text { RIRR (sirolimus } v \text { paclitaxel) }\end{array}$ & $\begin{array}{l}0.05(0.02 \text { to } 0.14) \\
0.09(0.03 \text { to } 0.24) \\
0.04(0.002 \text { to } 0.68) \\
0.02(0.001 \text { to } 0.37) \\
\text { NA } \\
0.06(0.03 \text { to } 0.12) \\
0.0 \%, p=0.77 \\
\text { NA } \\
\text { NA } \\
0.25(0.13 \text { to } 0.47) \\
0.30(0.17 \text { to } 0.53) \\
0.28(0.18 \text { to } 0.42) \\
0.0 \%, p=0.67 \\
0.21(0.10 \text { to } 0.48) \\
p<0.001\end{array}$ & $\begin{array}{l}0.20(0.11 \text { to } 0.34) \\
0.13(0.05 \text { to } 0.30) \\
0.03(0.002 \text { to } 0.54) \\
0.02(0.001 \text { to } 0.37) \\
0.11(0.04 \text { to } 0.28) \\
0.15(0.10 \text { to } 0.22) \\
8.8 \%, p=0.36 \\
\text { NA } \\
0.08(0.02 \text { to } 0.24) \\
0.35(0.20 \text { to } 0.59) \\
0.39(0.24 \text { to } 0.64) \\
0.32(0.23 \text { to } 0.45) \\
69.2 \%, p=0.04 \\
0.47(0.24 \text { to } 0.92) \\
p=0.027\end{array}$ & $\begin{array}{l}0.21(0.11 \text { to } 0.40) \\
0.20(0.08 \text { to } 0.52) \\
0.13(0.02 \text { to } 1.00) \\
0.02(0.001 \text { to } 0.41) \\
\text { NA } \\
0.19(0.11 \text { to } 0.31) \\
0.0 \%, p=0.52 \\
0.16(0.01 \text { to } 3.13) \\
0.29(0.14 \text { to } 0.61) \\
0.30(0.19 \text { to } 0.48) \\
0.49(0.27 \text { to } 0.88) \\
0.35(0.25 \text { to } 0.48) \\
0.0 \%, p=0.53 \\
0.54(0.30 \text { to } 0.99) \\
p=0.045\end{array}$ & $\begin{array}{l}0.39(0.25 \text { to } 0.62) \\
0.42(0.20 \text { to } 0.85) \\
0.13(0.02 \text { to } 1.00) \\
0.20(0.08 \text { to } 0.53) \\
\text { NA } \\
0.35(0.25 \text { to } 0.50) \\
0.0 \%, p=0.44 \\
0.28(0.03 \text { to } 2.53) \\
\text { NA } \\
\text { NA } \\
0.80(0.49 \text { to } 1.29) \\
0.76(0.48 \text { to } 1.22) \\
0.0 \%, p=0.37 \\
0.46(0.26 \text { to } 0.83) \\
p=0.010\end{array}$ \\
\hline
\end{tabular}

${ }^{*}{ }^{2}$, test of heterogeneity. 
Table 5 IRRs from trials of sirolimus and paclitaxel eluting stents and RIRR comparing sirolimus with paclitaxel in patients with diabetes

\begin{tabular}{|c|c|c|c|c|}
\hline \multirow[b]{2}{*}{ Study } & \multicolumn{4}{|c|}{ IRR ( $95 \%$ confidence interval) } \\
\hline & In-stent restenosis & In-segment restenosis & TLR & MACE \\
\hline \multicolumn{5}{|l|}{ Sirolimus trials } \\
\hline SIRIUS $(2003)^{4}$ & 0.17 (0.08 to 0.37$)$ & 0.35 (0.20 to 0.62$)$ & 0.31 (0.15 to 0.64$)$ & $0.37(0.19$ to 0.70$)$ \\
\hline E-SIRIUS (2003) ${ }^{1}$ & $0.13(0.03$ to 0.57$)$ & $0.19(0.06$ to 0.64$)$ & 0.21 (0.05 to 0.91$)$ & $0.27(0.08$ to 0.94$)$ \\
\hline C-SIRIUS $(2004)^{3}$ & $0.06(0.003$ to 1.02$)$ & $0.13(0.02$ to 1.00$)$ & $1.00(0.06$ to 15.99$)$ & $1.00(0.06$ to 15.99$)$ \\
\hline DIABETES $(2005)^{30}$ & $0.15(0.06$ to 0.39$)$ & $0.22(0.10$ to 0.47$)$ & $0.24(0.10$ to 0.59$)$ & $0.31(0.15$ to 0.66$)$ \\
\hline RAVEL $(2002)^{2}$ & $0.06(0.003$ to 0.97$)$ & $0.06(0.003$ to 0.97$)$ & $0.07(0.004$ to 1.19$)$ & $0.22(0.05$ to 0.98$)$ \\
\hline SES-SMART $(2004)^{8}$ & NA & $0.39(0.17$ to 0.91$)$ & NA & NA \\
\hline Combined IRR & $0.15(0.09$ to 0.25$)$ & $0.28(0.20$ to 0.41$)$ & $0.27(0.16$ to 0.45$)$ & $0.33(0.21$ to 0.51$)$ \\
\hline Heterogeneity* & $(0.0 \%, p=0.92)$ & $(0.0 \%, p=0.59)$ & $(0.0 \%, p=0.73)$ & $(0.0 \%, p=0.89)$ \\
\hline \multicolumn{5}{|l|}{ Paclitaxel trials } \\
\hline TAXUS I $(2003)^{5}$ & NA & NA & 0 events & 0 events \\
\hline TAXUS II $(2003)^{6,32,33}$ & NA & $0.07(0.004$ to 1.17$)$ & $0.16(0.02$ to 1.25$)$ & NA \\
\hline TAXUS IV $(2004)^{7,29}$ & $0.16(0.05$ to 0.48$)$ & 0.18 (0.07 to 0.49$)$ & $0.36(0.19$ to 0.70$)$ & NA \\
\hline TAXUS VI $(2005)^{31}$ & $0.20(0.05$ to 0.68$)$ & $0.23(0.08$ to 0.66$)$ & $0.20(0.04$ to 0.90$)$ & $0.55(0.21$ to 1.43$)$ \\
\hline Combined IRR & $0.18(0.08$ to 0.40$)$ & 0.19 (0.09 to 0.38$)$ & $0.31(0.18$ to 0.56$)$ & $0.55(0.21$ to 1.43$)$ \\
\hline Heterogeneity* & $0.0 \%, p=0.80$ & $0.0 \%, p=0.73$ & $0.0 \%, p=0.62$ & NA \\
\hline RIRR (sirolimus $v$ paclitaxel) & $\begin{array}{l}0.82(0.31 \text { to } 2.18) \\
p=0.694\end{array}$ & $\begin{array}{l}1.51(0.68 \text { to } 3.33) \\
p=0.312\end{array}$ & $\begin{array}{l}0.86(0.40 \text { to } 1.86) \\
p=0.703\end{array}$ & $\begin{array}{l}0.60(0.21 \text { to } 1.71) \\
p=0.336\end{array}$ \\
\hline
\end{tabular}

sirolimus trials than in the corresponding groups of the paclitaxel trials. If the relative reduction in restenosis risk strongly depended on the control group risk, this can partly explain the superior efficacy observed for sirolimus eluting stents. This is unlikely for several reasons. Recent head to head trials in patient populations that differed in terms of underlying risk consistently showed that sirolimus is superior to paclitaxel. ${ }^{14}$ Moreover, methodological research has shown that the relative reductions in risk associated with medical interventions tend be constant across patient populations with different underlying risks. ${ }^{51}$

\section{Conclusions}

This systematic review and meta-analysis shows substantial reductions in restenosis and revascularisation rates with the two widely used polymer based drug eluting stents, in both patients with and patients without diabetes. Sirolimus eluting stents appear more effective than paclitaxel eluting

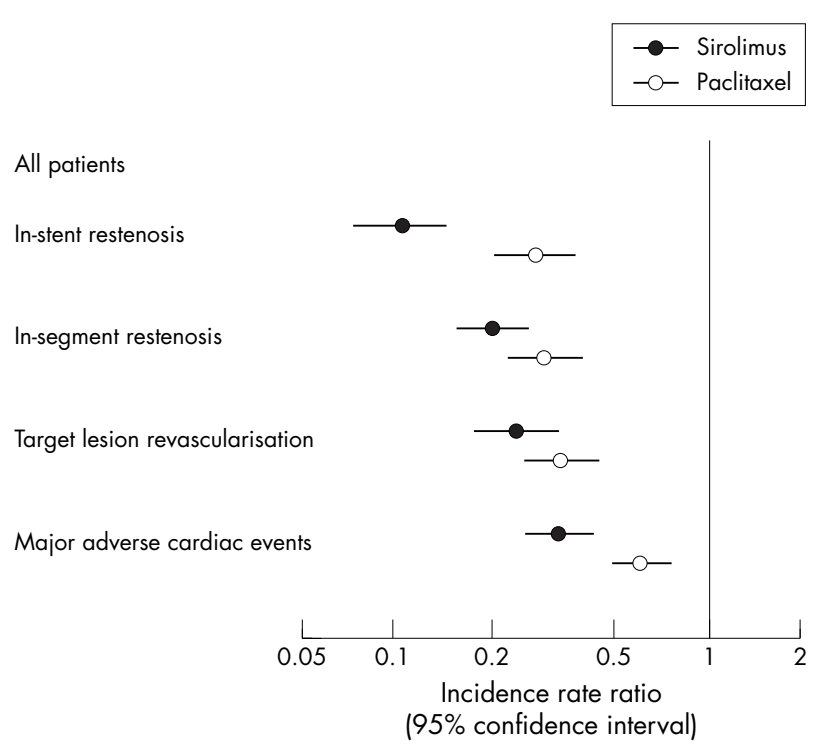

Figure 2 Effect of DES with sirolimus and paclitaxel compared with bare metal stents on the risks of restenosis, revascularisation, or adverse events. Combined estimates from meta-analyses of randomised controlled trials. stents in patients without diabetes, whereas efficacy appears to be comparable in patients with diabetes. We submit that a collaborative meta-analysis based on individual patient data

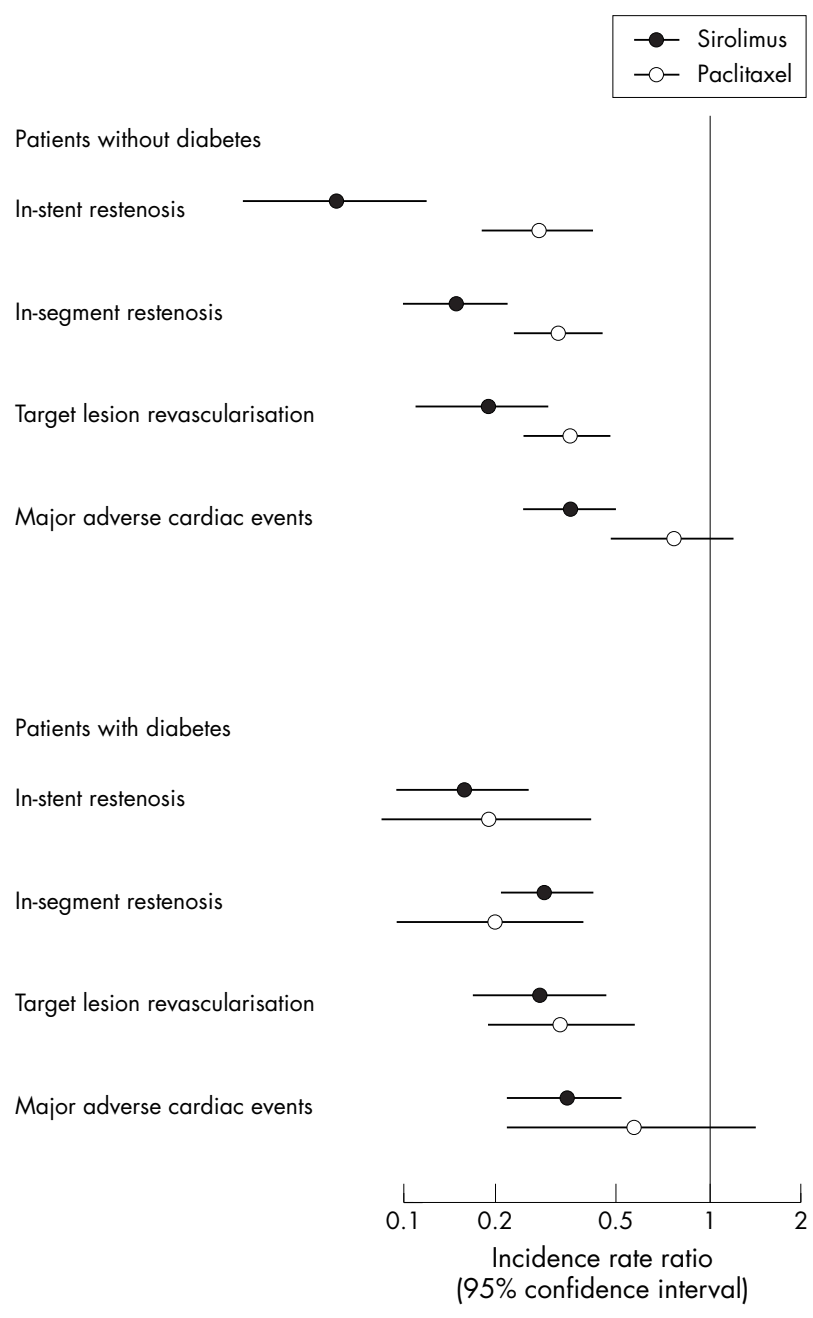

Figure 3 Effect of DES with sirolimus and paclitaxel in patients with and without diabetes. 
Table 6 Number of patients needed to treat during one year to prevent one adverse event

Number needed to treat (95\% confidence interval)

\begin{tabular}{llll}
\hline In-stent & $\begin{array}{l}\text { In-segment } \\
\text { restenosis }\end{array}$ & TLenosis
\end{tabular}$\quad$ MACE

Sirolimus eluting stent

Patients without diabetes 2.4 (2.3 to 2.6 ) 2.6 (2.5 to 2.9 ) 6.5 (5.9 to 7.6 ) 6.2 (5.3 to 8.0 )

Patients with diabetes $\quad 1.6$ (1.5 to 1.9$) 1.9$ (1.7 to 2.3$) 5.5$ (4.8 to 7.3$) 4.0$ (3.4 to 5.5 )

Paclitaxel eluting stent

Patients without diabetes 3.2 (2.8 to 3.9 ) 3.3 (2.9 to 4.0 ) 8.1 (7.0 to 10.1) 16.7 (NNTB 7.7 to NNTH 18.2)*

Patients with diabetes 1.7 (1.5 to 2.3 ) 1.7 (1.5 to 2.2) 5.8 (4.9 to 9.1$) 6.0$ (NNTB 3.4 to NNTH 6.3)*

*95\% confidence interval includes benefit and harm (number of patients needed to treat to prevent one event (NNTB); number of patients needed to treat to harm one patient (NNTH)). ${ }^{34}$

should be performed, which addresses the question whether the effectiveness of the two stents differs across patient groups with and without diabetes and, more in general, between patients at higher or lower risk of complications.

\section{ACKNOWLEDGEMENTS}

SA is supported by grants from Novo Nordisk, Roche Diagnostics, and GlaxoSmithKline. We are grateful to the trialists who provided additional data and checked the data we extracted from their publications.

\section{Authors' affiliations}

C Stettler, S Allemann*, M Eggert, Department of Social and Preventive Medicine, University of Bern, Bern, Switzerland

P Diem, Division of Endocrinology and Diabetes, University Hospital Bern, Bern, Switzerland

S Windecker, B Meier, Department of Cardiology, University Hospital Bern, Bern, Switzerland

*Also the Division of Endocrinology and Diabetes, University Hospital Bern, Bern, Switzerland

†Also the MRC Health Services Research Collaboration Department of Social Medicine, University of Bristol, Bristol, UK

Contributors: PD, CS, and ME conceived the study and wrote the protocol with help from SA. CS and SA searched the literature, contacted trialists, extracted data, and assessed the methodological quality of trials. CS, SA, and ME performed the statistical analyses. All authors contributed to the writing of the final draft of the manuscript. ME is the guarantor of this study.

Competing interests: none declared.

\section{REFERENCES}

1 Schofer J, Schluter M, Gershlick AH, et al. Sirolimus-eluting stents for treatment of patients with long atherosclerotic lesions in small coronary arteries: double-blind, randomised controlled trial (E-SIRIUS). Lancet 2003:362:1093-9.

2 Morice MC, Serruys PW, Sousa JE, et al. A randomized comparison of a sirolimus-eluting stent with a standard stent for coronary revascularization. N Engl J Med 2002;346:1773-80.

3 Schampaert E, Cohen EA, Schluter M, et al. The Canadian study of the sirolimus-eluting stent in the treatment of patients with long de novo lesions in small native coronary arteries (C-SIRIUS). J Am Coll Cardiol 2004;43: $1110-5$

4 Moses JW, Leon MB, Popma JJ, et al. Sirolimus-eluting stents versus standard stents in patients with stenosis in a native coronary artery. N Engl J Med 2003;349:1315-23

5 Grube E, Silber S, Hauptmann KE, et al. TAXUS I: six- and twelve-month results from a randomized, double-blind trial on a slow-release paclitaxeleluting stent for de novo coronary lesions. Circulation 2003;107:38-42.

6 Colombo A, Drzewiecki J, Banning A, et al. Randomized study to assess the effectiveness of slow- and moderate-release polymer-based paclitaxel-eluting stents for coronary artery lesions. Circulation 2003;108:788-94.

7 Stone GW, Ellis SG, Cox DA, et al. A polymer-based, paclitaxel-eluting stent in patients with coronary artery disease. N Engl J Med 2004;350:221-31.

8 Ardissino D, Cavallini C, Bramucci E, et al. Sirolimus-eluting vs uncoated stents for prevention of restenosis in small coronary arteries: a randomized trial. JAMA 2004;292:2727-34.
9 Babapulle $\mathrm{MN}$, Joseph L, Belisle $\mathrm{P}$, et al. A hierarchical Bayesian metaanalysis of randomised clinical trials of drug-eluting stents. Lancet 2004;364:583-91

10 Hill RA, Dundar Y, Bakhai A, et al. Drug-eluting stents: an early systematic review to inform policy. Eur Heart J 2004;25:902-19.

11 Indolfi C, Pavia M, Angelillo IF. Drug-eluting stents versus bare metal stents in percutaneous coronary interventions (a meta-analysis). Am J Cardiol 2005;95: 1146-52.

12 Windecker S, Remondino A, Eberli FR, et al. Sirolimus-eluting and paclitaxeleluting stents for coronary revascularization. N Engl J Med 2005;353:653-62

13 Dibra A, Kastrati A, Mehilli J, et al. Paclitaxel-eluting or sirolimus-eluting stents to prevent restenosis in diabetic patients. N Engl J Med 2005;353:663-70.

14 Kastrati A, Dibra A, Eberle S, et al. Sirolimus-eluting stents vs paclitaxeleluting stents in patients with coronary artery disease: meta-analysis of randomized trials. JAMA 2005;294:819-25.

15 Kannel WB, McGee DL. Diabetes and cardiovascular disease: the Framingham study. JAMA 1979;241:2035-8.

16 Stamler J, Vaccaro O, Neaton JD, et al. Diabetes, other risk factors, and 12-yr cardiovascular mortality for men screened in the multiple risk factor intervention trial. Diabetes Care 1993;16:434-44.

17 Carrozza JP Jr, Kuntz RE, Fishman RF, et al. Restenosis after arterial injury caused by coronary stenting in patients with diabetes mellitus. Ann Intern Med 1993; 1 18:344-9

18 Stein B, Weintraub WS, Gebhart SP, et al. Influence of diabetes mellitus on early and late outcome after percutaneous transluminal coronary angioplasty. Circulation 1995:91:979-89.

19 Detre KM, Guo P, Holubkov R et al. Coronary revascularization in diabetic patients: a comparison of the randomized and observational components of the bypass angioplasty revascularization investigation (BARI). Circulation 1999:99:633-40.

20 Scheen AJ, Warzee F. Diabetes is still a risk factor for restenosis after drugeluting stent in coronary arteries. Diabetes Care 2004;27:1840-1.

21 Scheen AJ, Warzee F, Legrand VM. Drug-eluting stents: meta-analysis in diabetic patients. Eur Heart J 2004;25:2167-8.

22 Campeau L. Grading of angina pectoris [letter]. Circulation 1976;54:522-3.

23 Hamm CW, Braunwald E. A classification of unstable angina revisited. Circulation 2000;102:118-22.

24 Higgins JP, Thompson SG. Quantifying heterogeneity in a meta-analysis. Stat Med 2002;21:1539-58.

25 Egger M, Davey SG, Schneider M, et al. Bias in meta-analysis detected by a simple, graphical test. BMJ 1997;315:629-34.

26 Thompson SG, Sharp SJ. Explaining heterogeneity in meta-analysis: a comparison of methods. Stat Med 1999;18:2693-708

27 Serruys PW, van Hout B, Bonnier H, et al. Randomised comparison of implantation of heparin-coated stents with balloon angioplasty in selected patients with coronary artery disease (Benestent II). Lancet 1998:352:673-81.

28 Van Hout BA, Serruys PW, Lemos PA, et al. One year cost effectiveness of sirolimus eluting stents compared with bare metal stents in the treatment of single native de novo coronary lesions: an analysis from the RAVEL trial. Heart 2005;91:507-12.

29 Stone GW, Ellis SG, Cox DA, et al. One-year clinical results with the slowrelease, polymer-based, paclitaxel-eluting TAXUS stent: the TAXUS-IV trial. Circulation 2004;109:1942-7.

30 Sabate M, Jimenez-Quevedo P, Angiolillo DJ, et al. Randomized comparison of sirolimus-eluting stent versus standard stent for percutaneous coronary revascularization in diabetic patients: the diabetes and sirolimus-eluting stent (DIABETES) trial. Circulation 2005;112:2175-83.

31 Dawkins KD, Grube E, Guagliumi G, et al. Clinical efficacy of polymer-based paclitaxel-eluting stents in the treatment of complex, long coronary artery lesions from a multicenter, randomized trial: support for the use of drugeluting stents in contemporary clinical practice. Circulation 2005; 11 12:3306-13.

32 Serruys PW, Degertekin M, Tanabe K, et al. Vascular responses at proximal and distal edges of paclitaxel-eluting stents: serial intravascular ultrasound analysis from the TAXUS II trial. Circulation 2004;109:627-33.

33 Tanabe K, Serruys PW, Degertekin M, et al. Chronic arterial responses to polymer-controlled paclitaxel-eluting stents: comparison with bare metal stents 
by serial intravascular ultrasound analyses: data from the randomized TAXUS-II trial. Circulation 2004; 109:196-200.

34 Altman DG. Confidence intervals for the number needed to treat. BMJ 1998;317:1309-12.

35 Finn AV, Palacios IF, Kastrati A, et al. Drug-eluting stents for diabetes mellitus: a rush to judgment? J Am Coll Cardiol 2005;45:479-83.

36 Corpus RA, George PB, House JA, et al. Optimal glycemic control is associated with a lower rate of target vessel revascularization in treated type II diabetic patients undergoing elective percutaneous coronary intervention. J Am Coll Cardiol 2004;43:8-14.

37 Gilbert J, Raboud J, Zinman B. Meta-analysis of the effect of diabetes on restenosis rates among patients receiving coronary angioplasty stenting. Diabetes Care 2004;27:990-4.

38 Song F, Altman DG, Glenny AM, et al. Validity of indirect comparison for estimating efficacy of competing interventions: empirical evidence from published meta-analyses. BMJ 2003;326:472.

39 Morice MC. Eight-month outcome of the REALITY study: a prospective randomized multi-center head-to-head comparison of the sirolimus-eluting stent (Cypher) and the paclitaxel-eluting stent (Taxus) [video]. American College of Cardiology, Annual Scientific Session 2005, Orlando, 6-9 March 2005. www.acc05online.acc.org/highlights/keyLectures.aspx? sessionld = $7890 \& \&$ date $=6$ (accessed 8 September 2005).

40 Hoffmann R, Mintz GS, Dussaillant GR, et al. Patterns and mechanisms of instent restenosis: a serial intravascular ultrasound study. Circulation 1996;94:1247-54.

41 Farb A, Heller PF, Shroff S, et al. Pathological analysis of local delivery of paclitaxel via a polymer-coated stent. Circulation 2001;104:473-9.
42 Schiff PB, Horwitz SB. Taxol stabilizes microtubules in mouse fibroblast cells. Proc Natl Acad Sci U S A 1980;77:1561-5.

43 Gallo R, Padurean A, Jayaraman T, et al. Inhibition of intimal thickening after balloon angioplasty in porcine coronary arteries by targeting regulators of the cell cycle. Circulation 1999:99:2164-70.

44 Burke SE, Lubbers NL, Chen YW, et al. Neointimal formation after ballooninduced vascular injury in Yucatan minipigs is reduced by oral rapamycin. $J$ Cardiovasc Pharmacol 1999;33:829-35.

45 Poon M, Marx SO, Gallo R, et al. Rapamycin inhibits vascular smooth muscle cell migration. J Clin Invest 1996;98:2277-83.

46 Kornowski R, Mintz GS, Lansky AJ, et al. Paradoxic decreases in atherosclerotic plaque mass in insulin-treated diabetic patients. Am J Cardiol 1998;81:1298-304.

47 Babinska A, Markell MS, Salifu MO, et al. Enhancement of human platelet aggregation and secretion induced by rapamycin. Nephrol Dial Transplant 1998;13:3153-9.

48 Levin AD, Vukmirovic N, Hwang CW, et al. Specific binding to intracellular proteins determines arterial transport properties for rapamycin and paclitaxel. Proc Natl Acad Sci U S A 2004;101:9463-7.

49 Kastrati A, Mehilli J, Dirschinger J, et al. Intracoronary stenting and angiographic results: strut thickness effect on restenosis outcome (ISARSTEREO) trial. Circulation 2001;103:2816-21.

50 Pache J, Kastrati A, Mehilli J et al. Intracoronary stenting and angiographic results: strut thickness effect on restenosis outcome (ISAR-STEREO-2) trial. J Am Coll Cardiol 2003;41:1283-8.

51 Deeks JJ. Issues in the selection of a summary statistic for meta-analysis of clinical trials with binary outcomes. Stat Med 2002;21:1575-600.

\section{IMAGES IN CARDIOLOGY}

doi: $10.1136 /$ hrt.2005.073668

\section{Unusual dominant course of left circumflex coronary artery with absent right coronary artery}

A single coronary artery is an unusual congenital anomaly where only one coronary artery arises from the aortic trunk by a single coronary ostium, supplying the entire heart. We describe here a rare case with an unusual dominant left circumflex artery and no right coronary artery.

A 43 year old man presented with atypical chest pain. His physical examination was unremarkable except for a blood pressure of 180/100 mm Hg. The ECG showed normal sinus rhythm without any ischaemic ST-T changes, and the treadmill exercise test also showed no evidence of ischaemia. Selective coronary angiography showed a normal left main coronary artery originating from the left sinus of Valsalva. However, the left circumflex coronary artery was a very dominant vessel and continued along the entire right side of the heart as the right coronary artery (panels A-C). There was no separate ostium for the right coronary artery as evident in the aortic root angiogram (panel D). There was no stenosis of any of the coronary arteries. The patient was discharged with antihypertensive medication.

Most coronary anomalies are accidentally identified during selective angiography. The separate origin ("absent left main") of the left anterior descending artery and left circumflex artery $(30.4 \%)$ and anomalous left circumflex artery $(27.7 \%)$ have been identified as the two most common coronary anomalies. Anomalous origin of the right coronary artery is also relatively common and has been described from various sites including the pulmonary trunk, aorta, left ventricle, and the sinus of Valsalva. However, continuation of the left circumflex artery along the entire right side of the heart with the absence of the right coronary artery, as occurred in our case, has never been described before. No regional wall motion abnormality was noted on echocardiogram and no collateral circulation from left to right was observed. These findings excluded the possibility of right coronary artery obstruction at its origin from the aorta.
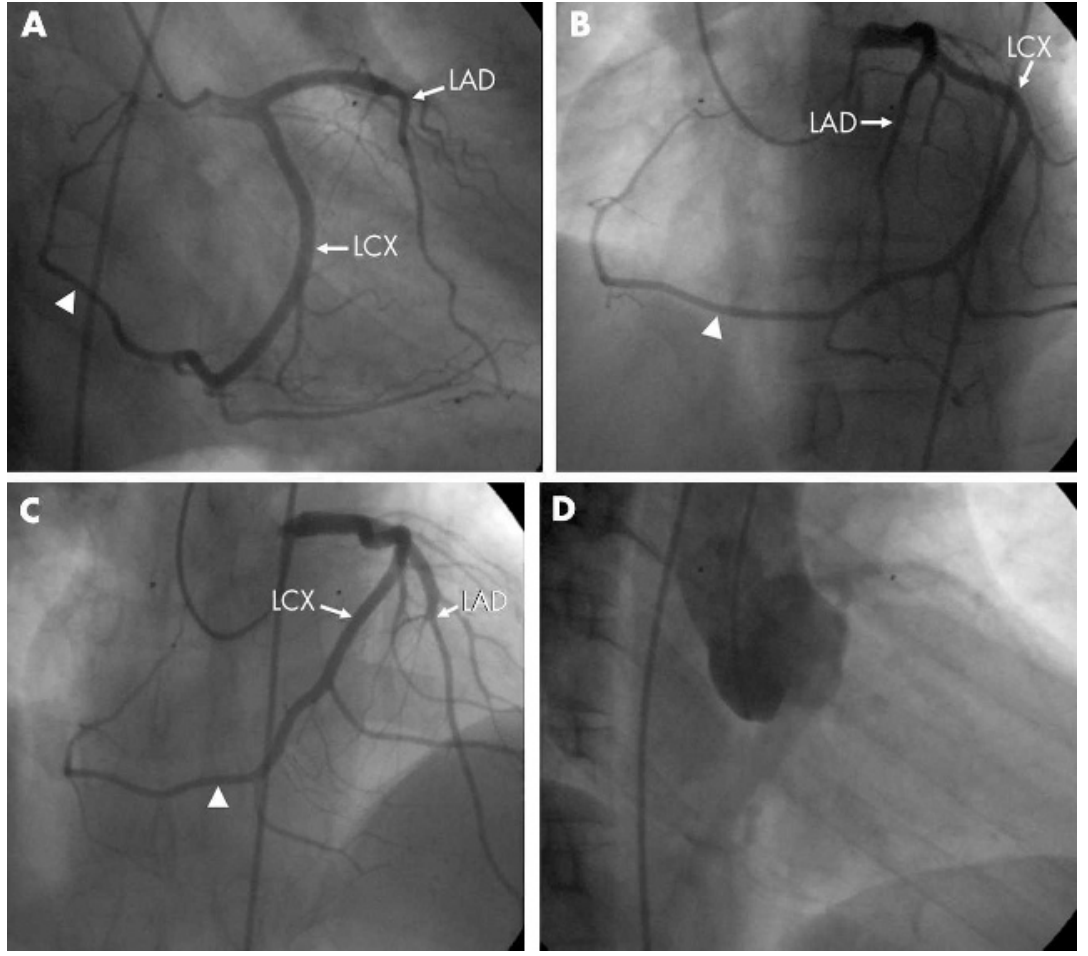

Selective left coronary angiogram in anteroposterior (AP) caudal view (A), left anterior oblique $\left(30^{\circ}\right)$ view (B), and AP cranial view (C). It shows that the left circumflex artery is very dominant and continues along the entire right side of the heart as the right coronary artery (white triangle). (D) Aortic root angiogram showing there is no separate ostium for the right coronary artery. $L A D$, left anterior descending artery; LCX, left circumflex artery; RCA, right coronary artery. 